\title{
Cooperative Learning Online in Higher Education. Second Experience at Roma Tre University, Italy
}

\author{
Concetta La Rocca \\ Department of Education, Roma Tre University, Rome, Italy \\ Email: concetta.larocca@uniroma3.it
}

Received 22 February 2015; accepted 5 April 2015; published 8 April 2015

Copyright (C) 2015 by author and Scientific Research Publishing Inc.

This work is licensed under the Creative Commons Attribution International License (CC BY). http://creativecommons.org/licenses/by/4.0/

(c) (i) Open Access

\section{Abstract}

This study presents the procedures and results of online cooperative learning activities carried out by the students in the a.y. 2013/14 in two academic courses at the Department of Education at Roma Tre University (Italy): “General Didactic” (GD), First-level Degree in Education Sciences and "Educational Strategies and New Communication Processes" (ES), Second-level Degree in Professional Community Educator. It constitutes the continuation of the first pilot study, carried out only in the teaching of GD in the academic year 2012/13 which has already been reported in a previous publication [1]; this second experience is built in a perspective of continuity and difference from the first one. This study is divided into two interventions: a) description and analysis of the data collected following the administration of a questionnaire, said barometer, developed to detect the climate experienced by the students involved in the online working groups; b) investigation of the relapse that collaborative activities produced on the performance. In particular, we observe that the average mark obtained in the exam of "General Didactics" by the students in cooperative is on average higher than others, and that in the first group there is less "sigma" compared to the second group.

\section{Keywords}

Online Cooperative Learning, Barometer, Online Tutoring

\section{Introduction}

In a recent article of 2014, Johnson, Johnson, \& Smith [2] propose a meta-analysis of some studies on cooperative learning conducted from the sixties of the twentieth century to the first decade of the twenty-first century in 
different universities, particularly in North America, but also in the Middle East, Europe and Asia.

Comparing the results of the different studies (305), the authors note that cooperative learning promotes greater individual achievement than competitive learning (increase $=0.49$ ) and individualistic (increase $=0.53$ ). The authors point out that these increases are significant and substantial; they also identify the elements of individual achievement according to the following descriptors: acquisition and preservation of knowledge; precision and creativity in problem solving, achieving a higher level of reasoning. These results were achieved by students in performing verbal tasks (such as reading, writing, and oral presentation), mathematical operations and physical activities (such as swimming, golf and tennis). They also point out that some studies showed how cooperative learning provided an advantage in promoting the meta-cognitive thinking, in the readiness to perform difficult tasks, in devoting more time to the task, in perseverating (despite possible difficulties) in achieving goals, in transferring the knowledge gained from one situation to another [3]. The authors also underlined that these results are confirmed in a meta-analysis carried out on studies focused on the analysis of the application of cooperative learning in academic courses of science, mathematics, engineering, and technology [4]. Finally, it is interesting to cite some studies that show that the quality of university life may depend largely on the quality of relationships among students and between students and teachers [5]-[8]. The positive interpersonal relationships can increase the quality of social adaptation to university life, as well as develop in students a sense of intellectual belonging towards the institution, reduce the inconsistencies between the interests of the students and the study curriculum, promote integration in the academic life and the commitment to complete the course of study.

Furthermore, the research indicates that the benefits of cooperative learning can be transferred in virtual environments created on the network [9]. McConnell [10]-[13] in his various studies on the subject, provides many examples of collaborative learning systems constructed to support the communication and the sharing of documents in synchronous and asynchronous modes. Of course the success of the activities in cooperative learning depends on an appropriate design of teaching methods, which should enable students to share their work [14], also in the university. Within the design of cooperative learning, Smith \& Coenders [15] consider necessary to envisage the construction of an instrument to collect data on the activities of group work online. They detect in the so-called community barometer, a questionnaire to be administered to participants, the tool to get a feedback on their experience [16]. The barometer allows students to identify themselves as an online learning community, and enables educators to receive information on the climate generated within the group, as well as offering them the opportunity to correct any critical issues. The barometer used in this experience has been built by the author of this work and its standardization is expected in a future study.

\section{Description of the Study}

\subsection{Reasons Implied in the Study}

This experience is based on the assumption that the experience of online collaborative learning at university helps students to develop the meta-cognition required to successfully complete their own learning.

Online collaborative learning activates practice of positive interdependence, enhances motivation and reduces the anxiety associated to the exam. In this way it facilitates the inclusion of students in the university world and enables them to stem the drop-out and become more aware of the academic journey they undertook.

\subsection{Methodological Approach}

As mentioned in the Abstract, this work presents the procedures and results of online cooperative learning activities carried out by the students in the academic year 2013/14 within the two courses: “'General Didactic' (GD) for the First-level Degree in Education Sciences and "Educational Strategies and New Communication Processes” (ES) for the Second-level Degree in Professional Community Educator.

In analogy with the pilot study of academic year 2012/13, this second study consists of an empirical observation of the process and the product of the training in two perspectives: the monitoring of the climate in the group and the result obtained at exam of GD.

In particular, it presents the results obtained by implementing the ideas expressed in the concluding remarks of the previous study, namely: to extend the experience to other courses; to simplify the questionnaire, said barometer, used for monitoring; to administer the barometer not only at the end of but also during the course to give students an interim feed-back and to observe, in progress, the expectations of the students and their opinions 
on their experience; to observe if on average there was an increase in the results achieved by students in the examination of the GD, comparing the outcomes of those who participated in collaborative activities with those who did not take part in them.

Both courses (GD and ES) are held in blended form (presence and distance learning) and the experience of cooperative learning concerns the online activities.

The choice of GD and ES was made out of common features between the two courses and of reasons related to their specificity.

The common reasons can be summarized as follows:

- blended form structure: each course implies the execution of some online activities;

- consistency of the theme of the survey with the contents treated in the course.

The specific reasons are the following:

- GD is designed for first-year students who, being freshmen, often show a certain confusion in understanding the academic dynamics. This distress is increased by the large number of students attending to the course (over 300). It was decided, therefore, to promote a cooperative learning experience, to facilitate the integration of the freshmen, as well as to encourage their motivation to study, reduce the anxiety associated with the exam and promote positive interaction among students.

- ES belongs to a Second-level Degree and is therefore designed for students who will refine the professional techniques appropriate to the management of the workplace as Community Educators. By attending this course, students will learn the theoretical foundations that underlie the construction and the development of online professional communities and will learn to design intentionally structured interventions with the help of ICT. So they learn both how to build educational online frameworks and how to build effective online communication situations for the professional team. Therefore, participation in online cooperative learning activities allows them to simulate some future professional contexts.

In line with the specificity of the content treated in the two courses and with the learning outcomes expected, the online activities of cooperative learning have been made optional in GD and compulsory in ES.

It was also decided to provide the activities of cooperative learning online to allow even non-attending students the opportunity to meet colleagues through the forums and to organize the common work with them.

\subsection{Description of the Activities Carried out by Teachers and Students}

The teacher of each course (GD \& ES) introduces students to the activities to be carried out in the group work; he presents a summary of the theories and teaching strategies that deal of cooperative learning, with particular reference to cooperative learning and peer tutoring. The seminar is held in the presence with the support of slides and multimedia materials; the same materials used during the lessons are insert in the online platform so that the students, attending or not, can obtain continuous access to information and can discuss with the teacher and with each other in the specific forum.

The teacher, in his seminar, indicates the goals that each student will have to pursue in the group work, and distinguishes the goals for macro-categories: 1) cognitive and metacognitive, 2) affective and relational. The first (cognitive and metacognitive) aim to promote the use of descriptive language appropriately using the terms typical to the scientific areas, the identification of relevant information, the execution of comparisons, the comparison of information and data by analogy and opposition, the awareness of function performed by the cooperative work in the construction of knowledge, the ability to synthesize materials in a final document, the reflection on the contribution of each subject to the realization of the final product. The affective and relational goals concern the acquisition of the capacity for dialogue and active listening, for communicating content and emotions with the aim to establish a mutual support in the learning process.

Furthermore, in the introductory seminar, the teacher indicates the steps necessary for the formation of work-groups and for the preparation of the online and presence activities. The online work-groups actually started about at the middle of the course, in order to enable students to acquire knowledge elements related to the course content and become familiar with each other online and in presence.

Considering the context of university, the groups are formed independently by the students themselves on the basis of shared interests, but following the teacher advice, namely: do not exceed five units per group; propose a topic to work on to the teacher; decide which name attribute to their own group; identify a student who will act as coordinator and one who will edit the final work. 


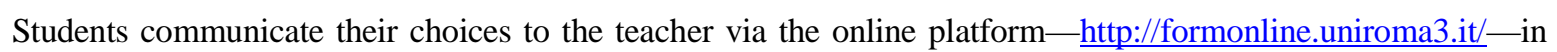
the spaces reserved for Courses of GD and ES. Here the teacher opens a forum for each group where the students can communicate and exchange ideas and materials online.

The management of the forum is organized differently in the two courses: in GD the teacher and the experts with tutorial functions intervene only in response to explicit requests, with a marginal supporting, almost by presence/hidden or better "lurking", ready to act if it needed, but be careful not to weaken the dimension of peer tutoring, even promoting and encouraging it, considering the students as pares inter pares. In ES it has instead opted for the establishment of an institutional expert tutor that performs continuous functions of moderation and support for individual groups both online and in presence.

After establishing the groups, the selection of topics to be explored, the attribution of the forum and tutors, the date for the beginning of the work-group is communicated to the students; all work must be completed within the time schedule. Finally the day in which each group must present, in a conference style, the document produced consisting or in a hypertext, or in a PowerPoint, or in a wiki text or an interactive concept map, is fixed.

\subsection{Barometer for Monitoring the Activities in Cooperative Learning Online}

The monitoring was carried out by administering a short questionnaire working as a barometer which gathered the opinions of students about the experience they lived in cooperative activities.

Scientific literature indicates a barometer as a tool for the detection of self-perception of the climate in the group; it is generally used to give the teacher and the students themselves a feedback on relational and productive actions that took place in the group. As reported in the literature, there are cases in which a barometer is perceived by the participants as a nuisance or an intrusion, therefore in the first experience, which took place last year, it was decided to administer the barometer only at the end of the training process. As mentioned in Paragraph 2.2, in this second experience it is decided to administer the barometer to students two times, first after about two weeks from the start of group activities and then at the end of the same. This dual administration has allowed us to make a comparison between the expectations that students placed in cooperative activities and their opinions matured after the performance of the same.

It is also need to emphasize that within the first experience the barometer was built with a preeminence of open-ended questions to allow greater freedom of expression and therefore to collect useful information for the preparation of a more agile and structured tool to be used in future equivalent investigations. To gain comparable data, it is proceeded to a reconfiguration of the open questions, turning the free answers, previously provided by the students, into answer alternatives in closed questions. There remained, however, the option of an open alternative answer in each closed-question, to allow the students more freedom all along the questionnaire. The barometer in ongoing contains the same questions of the one in outgoing, with the only variation of temporal forms that express the expectation on the first one and of the statement in observed and experienced facts on the second one.

The barometer administered during last a.y. (2012/13) consisted of 10 questions: the first three (A, B, C) were structured with four predetermined responses articulated according to a Likert scale with four levels (Very, Enough, Little, Not at all); the others (D, E, F, G, H, I, L) were open questions with free answers; the questionnaires analyzed were 48. The coding and decoding of the data was conducted in SPSS, with retrospective procedures codification using macro-categories for answers to open questions and with conventional procedures for quantitative answers to closed questions.

The barometer used in this second trial (2013/14), consists of 10 questions: the first three (A, B, C) are structured questions, each of them providing predetermined responses articulated according to a Likert scale with four levels (Very, Enough, Little, Not at all); the others (D, E, F, G, H, I, L) are structured questions with multiple choice alternatives, derived from the free answers provided by students during the first trial. Particularly, the question A calls for a reflection on the relational context; B on the learning contents; $\mathrm{C}$ on the management of the work; D (which is divided into D1, D2, D3) and E concern the skills deemed necessary to tackle the experience; the questions F, G, H investigate on the role of the subject in the group and on the relationship between the subject and the group; the questions I and $\mathrm{L}$ require to indicate any problems encountered and to offer some advice for improving the experience. The totality of the alternatives of the default responses, and variously distributed for each question, is 61 .

As last year the survey of the outcomes of GD exam was focused on the observation of the final vote obtained 
by the students participating in the cooperative activities in relation to the vote obtained by the students who did not participate. Even in the second trial this comparison was carried out for GD only, because ES compels students to carry out online cooperative activities which correspond to 3 of the Credits allocated to the course.

To summarize, this second study consists in an empirical observation of the process and of the product of the training according to two perspectives: the monitoring, through the barometer, of the climate settled in the working groups formed within the GD and ES courses and the detection of the examination result in GD.

\section{Analysis and Interpretation of the Empirical Data}

The number of questionnaires returned and analyzed is the following:

- General Didactic/on-going $=63$

- General Didactic/out-going $=67$

- Educational Strategies and New Communication Processes/on-going $=40$

- Educational Strategies and New Communication Processes/out-going $=38$

The coding and decoding of the responses was conducted in SPSS, with retrospective codification using macro-categories for answers to open questions and with conventional procedures for quantitative answers to closed questions.

The questionnaires were entered maintaining the two courses separate, so to allow the following processing of descriptive statistics for each course: univariate analysis of the on-going and out-going questionnaires to allow diachronic comparison between expectations and outcomes; bivariate analysis for out-going questionnaires only, to observe, synchronously, the actual outcome of the experience compared to specific issues; multivariate analysis for out-going questionnaires only to represent the data position related to selected barometer items on a Cartesian axis, according to a specific perspective.

Generally the results obtained from the administration of the barometer have been very positive and were no large gaps between input and output opinions or between the expectations towards cooperative learning and the realization of activities in the group, except for some cases that will be highlighted.

In particular, concerning questions $\mathrm{A}$ and $\mathrm{B}$, students considered that cooperative activities have allowed the construction of relations of positive interdependence, improved the relationship with the teacher and given a favorable disposition towards the exam. They also expressed the opinion that it would be interesting to have group-work activities also in other courses, as the documents research was useful and interesting and that indepth analysis has enhanced their learning because the team-work "forced" them to reflect on their own comprehension processes.

It is interesting to observe that within GD, as far as the option "It would be interesting to practice groupworks in other teachings" in question B is concerned, the out-going barometer has increased by $+3.4 \%$, and in the context of ES, the alternative "The team-work will force/help you to reflect on your learning process" has achieved an increase of $+2.4 \%$. Evidently the students of GD, as freshmen, found support in team-work and hope to find the same in other courses; on the other hand, the masterful students of ES have especially perceived the metacognitive dimension in cooperative work.

As to the question C, which asks "The opinion of the students on the management of group-work", it is interesting to note that the option "In the work-group could develop Competition" has had a decrease in the outgoing barometer compared to the on-going: in GD it has decreased by $-21.3 \%$ and in ES by $-19.5 \%$; therefore students have experienced that, in practice, working in groups can generate no competition.

As to the question D, most of the students identified the "Cognitive skills necessary to work in group" in the awareness of their own competences and in the sharing of their own knowledge; they also individuated social skills in listening to the others and respecting the ideas of others. It is therefore possible to build a climate of collaboration that allows organizing work and positive management of conflicts through emotional commitment, confidence, determination and sense of responsibility.

In this case within GD the gap between the most significant responses between the on-going and the outgoing barometer is the increase of the "Awareness of their competences" $(+3.3 \%)$ and "Confidence" $(+4.8 \%)$ abilities and a decrease of the "Conflict handling" $(-13 \%)$ and "Patience" $(-4.5 \%)$ abilities; the pupils thought at first that working in groups would require a persevering effort in managing conflict, and have instead found out that it needs more confidence and patience. Students of ES have answered at 100\%, both on-going and out-going barometer, that to work in a group "Awareness of your competences" is a must-have, but there is an increase in the out-going about the "Listening" $(+13.8 \%)$, "Patience" $(+4.3 \%)$, "Sharing your knowledge" 
$(+1.7 \%)$ skills. So the data show that, comparing to the forecast, they understood that to work in group the personal poise is not enough, but it is necessary to give space to relationship.

The answers to the question $\mathrm{E}$ put in evidence that most of the students consider that the ability to work in a group can be acquired through experiences similar to the one they lived, and noted that within each group everyone has done his/her homework in different ways by taking their own responsibility negotiating with work mates.

For both the courses, a bivariate analysis between each of the answer's alternative provided in the item D and in the E has been carried out: the outcome was almost the same for every intersection, namely the higher percentage of students felt that each skill, listed in D, could have been acquired and developed through experiences similar to this done.

The question $\mathrm{H}$ asked whether students prefer to study in group or alone. The most part responded that they prefer collective study to optimize the working times, to exchange ideas and opinions, to become aware of the contents that are mastered and of those to delve deeper into. Some students have pointed out that individual study is not to be considered as an alternative to group study, and that the individual study may be preferable if you must face a test that requires special personal reworking.

In particular, for GD students, the group work experience was satisfactory especially for the content sharing and the reflection about it, while students of ES found positivity in teamwork, both in meta-cognitive and in social relation dimension.

Answers to questions I and L have been crossed-check; question I asked students to indicate any problems that emerged in their experience and L question asked them to offer some suggestions to solve such problems.

The $67.2 \%$ of students in GD did not detect any critical element in the online cooperative learning experience. The remaining $36.8 \%$ indicated that the mainly critical issue concerned especially the choice of components of the group (11.9\%), because not everyone has done the same amount of work (19.4\%). They also suggested to enhance the role of the tutor and/or of the teacher to help the group to manage the physical distance, and to provide a valuable support in overcoming any difficulties.

The $68.4 \%$ of students in SE believes that there were no critical elements. In comparison with the answers in GD, the most important fact that emerges is that no one has suggested strengthening the role of the tutor or the teacher. Probably this is because in this course the figure of an "institutional" tutor to whom students can refer had already been set up; the tutor allowed a better balance in the groups so a decrease in the percentage of those who believe that not everyone has contributed in equal measure to the work (8\%) has also been observed.

As it had previously been done for the experience of 2012/13, a multiple correspondence analysis among items requiring considerations about "the organization of group-work" has been carried out. The results of the analysis regarding GD are shown in Figure 1, and those regarding ES in Figure 2.

The letters and the numbers shown on the Cartesian plane correspond to questions and to their answers respectively; in order to facilitate the understanding of the interpretation that will be proposed, the text of the questions and of the answers that correspond to the points contained in the circles are shown in the box beside the diagram (eg F-3 = Question F, answer 3; eg C1-4.1. = Question C1, answer 4, Likert scale value 1).

Looking at the graph, the first evidence regards the aggregation density around the point 0 ; where the positive

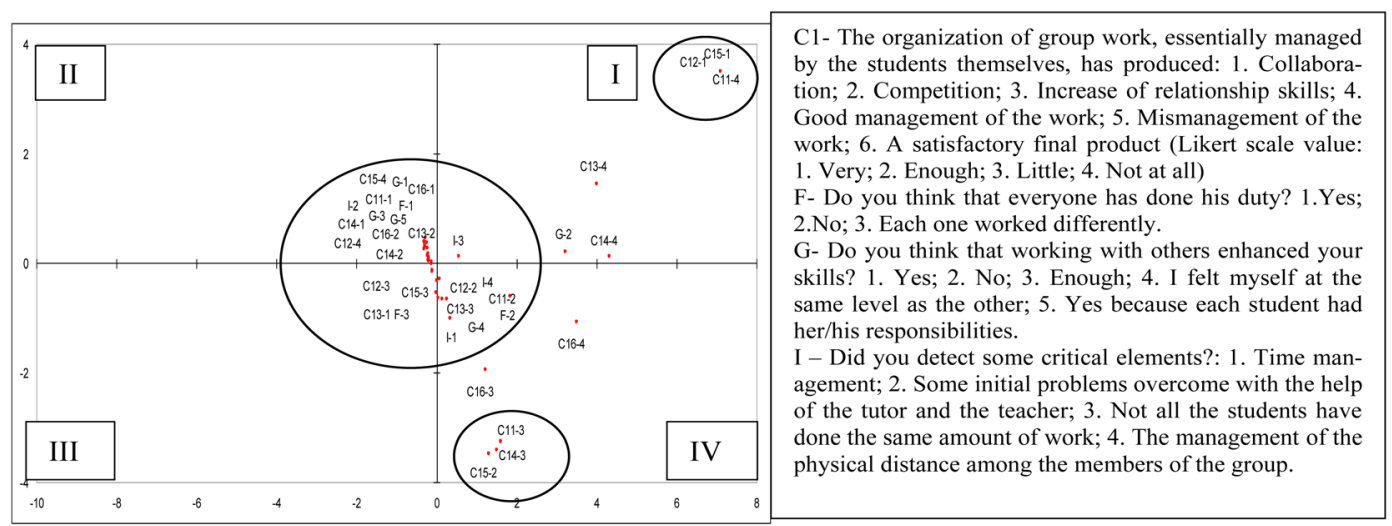

Figure 1. General Didactic-The organization of group-work: Multivariate analysis. 


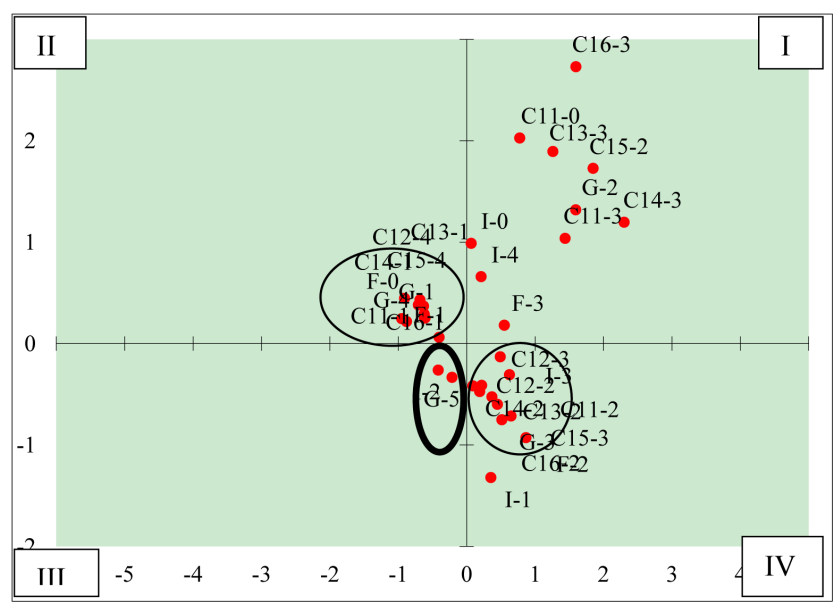

C1- The organization of group work, essentially managed by the students themselves, has produced: 1. Collaboration; 2. Competition; 3. Increase of relationship skills; 4. Good management of the work; 5. Mismanagement of the work; 6. A satisfactory final product (Likert scale value: 1.Very; 2. Enough; 3. Little; 4. Not at all)

F- Do you think that everyone has done his duty? 1.Yes; 2.No; 3 . Each one worked differently.

G- Do you think that working with others enhanced you? 1. Yes; 2. No; 3. Enough; 4. I felt myself at the same level as the other; 5 . Yes because each student had his responsibilities.

I - Did you detected some critical elements?: 1. Time management; 2 . Some initial problems overcome with the help of the tutor and the teacher; 3 . Not all the students have done the same amount of work; 4 . The management of the physical distance among the members of the group.

Figure 2. Educational Strategies-The organization of group-work: Multivariate analysis.

evaluations expressed by the majority of students are placed; they felt that the experience of cooperative learning online has developed cooperation, increase of relational skills, also producing a final satisfactory work; these students stated that they felt endorsed in an environment where everyone took charge of their responsibilities by engaging in their work. Two other small areas of aggregation can be seen; the first in the upper right quadrant (I) where there are definitely negative answers, the second in the quadrant IV, where there are the answers that express moderated criticality. Definitely negative answers express the position of those few students who felt that this experience has encouraged competition rather than collaboration and that the work in the group was handled very badly. To explore the question, a qualitative analysis of the data has been carried out; it was found that negative feedback belonged to three boys in the same group. They started enthusiastically to work on the tasks required, but in the last phase there were some problems that prevented them from completing their activities and presenting their final work. In particular, one of them has not done his part of work preventing the others to achieve the goal. This probably explains the reason why they have expressed such strong negative judgments on their experience.

The graph of the multivariate analysis regarding the ES course shows, in quadrant II, the students responses which affirm that the organization of group work has been "very" positive and, in quadrant IV, the "enough" positive answers. The interesting data is in quadrant III, where there are the assertions "There were initial problems then overcame with the help of the tutor" and "I felt enhanced by the group work because each one has assumed his responsibilities" have resulted to be in a near position. These statements are equidistant from both the very positive feedback and the positive ones, so it seems fair to say that they are shared by both groups.

The reading of the multivariate analysis confirms the information taken from both the univariate and bivariate ones, which showed a certain problematic in the course of GD, especially about the difficulty of managing the relationship among the members of the group both in relational field and on the taking charge of individual responsibility in the working activity. As already told, the presence of an institutional tutor in the course of ES has helped students to create a situation of online cooperation more relaxed and effective.

Figure 3 shows the result of the marks in the exam for the students in GD: the difference between the mark received by the students who participated in the online cooperative activities and the mark of students who did not participate was observed.

The same survey could not be made for ES because in this course all students compulsorily participated in the activities of cooperative learning online.

As for 2012/13, even for 2013/14, the statistical study of the data is purely descriptive and exploratory. From the comparison of the box plot (Figure 3) it is possible to confirm the result obtained the last year: the average rating received by the students of the second group is higher than the first group's one, and in the second group there is a lower variability of the votes among the individual marks.

\section{Findings and Future Perspectives}

The experimentation of activities carried out in university cooperative learning online in 2013/14 was essentially 


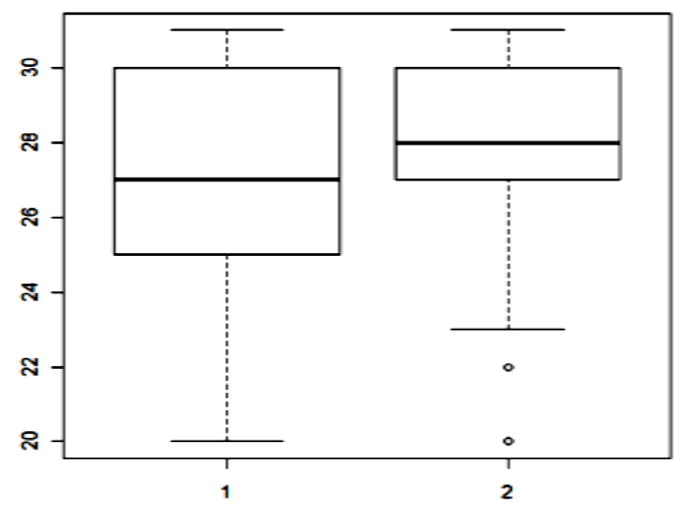

1: students who have not participated in the groups (211 students, average rating $=27 ;$ standard deviation $=2.71$ )

2 : students who participated in the groups ( 78 students, average rating $=$ 28 ; standard deviation $=2.45$ )

\section{Figure 3. Box-Plot-testing result of general didactic 2013/14.}

very positive, as it was the pilot experience of the academic year 2012/13: students felt themselves involved in the learning process and in the construction of the course through the topics developed in group work.

Students verified that the group work helps to develop cognitive, meta-cognitive and social skills, and said that similar experiences are desirable in their academic path. Moreover the operations of analysis, synthesis, evaluation and correction of the online path followed, the materials elaborated, the public in the presence display of their final work, have helped to strengthen their self-esteem, a sense of belonging to a learning community and a positive disposition towards the discipline and the final exam.

It was also observed, in the comparison between the two courses, that the presence of a disciplinary tutor, who acted as a systematic and continuous support, helped to create a climate of greater cooperation related to the undertaking of individual responsibility in the performance of assigned tasks.

Even if the experience was definitely positive in its management and its outcomes, a critical element was however noted in the inability to process the data of the on-going barometer in time to provide a feedback to students on the progress of online cooperative learning activities; in fact the results obtained by the administration of the ongoing and out-going barometer have been useful only for scientific observation of the experience.

In the future it would be desirable to incorporate the activities of online cooperative learning in other courses, so to train students to cooperation, active listening, sharing of knowledge and skills, as well as to offer them an area of aggregation and dialogue using an e-learning platform.

\section{References}

[1] La Rocca, C., Margottini, M. and Capobianco, R. (2014) Collaborative Learning in Higher Education. Open Journal of Social Sciences.

[2] Johnson, D.W., Johnson, R.T. and Smith, K. (2014) Cooperative Learning: Improving University Instruction by Basing Practice on Validated Theory. In: Davidson, N., Major, C. and Michaelsen, L., Eds., Small-Group Learning in Higher Education: Cooperative, Collaborative, Problem-Based and Team-Based Learning. Journal on Excellence in College Teaching, 25(4).

http://personal.cege.umn.edu/ smith/docs/Johnson-Johnson-Smith-Cooperative_Learning-JECT-Small_Group_Learni ng-draft.pdf

[3] Johnson, D.W. and Johnson, R. (1989) Cooperation and Competition: Theory and Research. Interaction Book Company, Edina.

[4] Springer, L., Stanne, M.E. and Donovan, S.S. (1999) Effects of Small-Group Learning on Undergraduates in Science, Mathematics, Engineering, and Technology: A Meta-Analysis. Review of Educational Research, 69, 21-51. http://dx.doi.org/10.3102/00346543069001021

[5] Astin, A. (1993) What Matters in University: Four Critical Years Revisited. Jossey-Bass, San Francisco.

[6] McKeachie, W., Pintrich, P., Yi-Guang, L. and Smith, D. (1986) Teaching and Learning in the University Classroom: A Review of the Research Literature. The Regents of the University of Michigan, Ann Arbor.

[7] Pascarella, E. (2001) Cognitive Growth in University. Change, 33, 21-27.

[8] Tinto, V. (1993) Leaving University: Rethinking the Causes and Cures of Student Attrition. 2nd Edition, University of Chicago Press, Chicago. 
[9] Calvani, A. (2005) Rete, comunità e conoscenza. Costruire e gestire dinamiche collaborative. Trento, Erickson.

[10] McConnell, D. (2000) Implementing Computer Supported Cooperative Learning. 2nd Edition, Kogan Page, London, $264 \mathrm{p}$.

[11] McConnell, D. (2005) Examining the Dynamics of Networked E-Learning Groups and Communities. Studies in Higher Education, 30, 23-40. http://dx.doi.org/10.1080/0307507052000307777

[12] Bradley, S.A. and McConnell, D. (2008) Virtual Groups in Learning Environments: Collaboration, Cooperation or (Self) Centred Individualism? Proceedings of the 6th International Conference on Networked Learning, 24-31. http://www.networkedlearningconference.org.uk/abstracts/PDFs/Bradley_24-31.pdf

[13] Crosta, L. and McConnell, D. (2008) Online Learning Groups Development: A Grounded International Comparison. Proceedings of the 6th International Conference on Networked Learning, 61-68.

[14] Koschmann, T. (Ed.) (1996) CSCL: Theory and Practice of an Emerging Paradigm. Lawrence Erlbaum, Mahwah. http://www.networkedlearningconference.org.uk/abstracts/PDFs/Crosta_61-68.pdf

[15] Smith, J. and Coenders, M. (2002) E-Feedback to Reflect Legitimate Peripheral Participation; Towards a Redefinition of Feedback in Online Learning Environments. In: Driscoll, M. and Reeves, T., Eds., Proceedings of World Conference on E-Learning in Corporate, Government, Healthcare, and Higher Education 2002, 878-890.

[16] Arnold, P. and Smith, J. (2003) Adding Connectivity and Losing Context with ICT: Contrasting Learning Situations from a Community of Practice Perspective. In: Huysman, M., Wenger, E. and Wulf, V., Eds., Communities and Technologies-Proceedings of the First International Conference on Communities and Technologies, C\&T 2003. 